\title{
Quantification of lung collapse during peep- titration by electrical impedance tomography in experimental ards - comparison with quantitative ct analysis
}

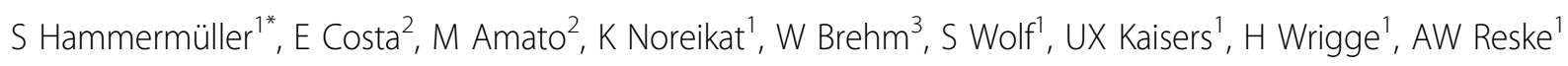

From ESICM LIVES 2015

Berlin, Germany. 3-7 October 2015

\section{Introduction}

Tidal recruitment of nonaerated lung is a main cause of ventilator associated lung injury. $\mathrm{CT}$ as the gold standard for quantifying lung collapse (CT-collapse) is associated with certain risks for the patient (e.g. radiation exposure or transportation) and cannot be used for repeated assessments. Electrical impedance tomography (EIT) instead is a bed-side non-invasive radiation-free continuous technique for monitoring of changes in thoracic air content and distribution. EIT may also allow quantification of recruitable lunge collapse (EIT-collapse) [1].

\section{Objectives}

To study correlation and agreement between CT- and EIT-collapse during a decremental PEEP-titration after a lung recruitment maneuver (RM) for further validation of the technique for assessment of EIT-collapse.

\section{Methods}

We induced ARDS in anesthetized pigs by pulmonary acid $(\mathrm{HCl})$ instillation until the $\mathrm{PaO}_{2} / \mathrm{FiO}_{2}$ remained stable $<200 \mathrm{mmHg}$. Tidal volume was $6 \mathrm{ml} / \mathrm{kg}$ body weight. We performed a RM (PEEP $40 \mathrm{cmH}_{2} \mathrm{O}$; PIP $60 \mathrm{cmH}_{2} \mathrm{O}$ for $2 \mathrm{~min}$ ) followed by decremental PEEPtitration (starting from $26 \mathrm{cmH}_{2} \mathrm{O}$ in steps of $2 \mathrm{cmH}_{2} \mathrm{O}$ ). We recorded EIT-data and airway pressures simultaneously on each step and obtained end-expiratory CTs. CT-collapse in the entire lung was defined as the lung mass within $-200 \mathrm{HU}$ to $+100 \mathrm{HU}$ [2]. "Non-recruitable collapse" was defined as CT-collapse remaining after
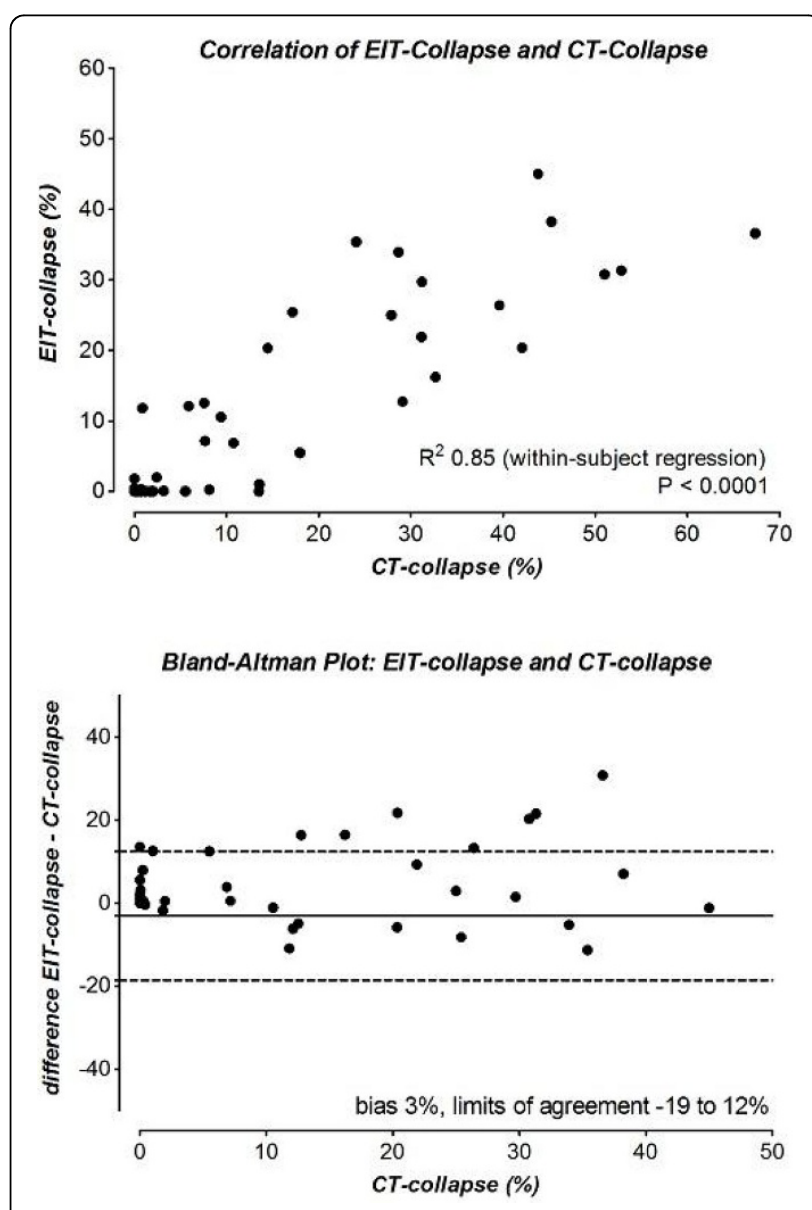

Figure 1

${ }^{1}$ University Leipzig, Department of Anesthesiology and Intensive Care

Medicine, Leipzig, Germany

Full list of author information is available at the end of the article

(c) 2015 Hammermüller et al.; This is an Open Access article distributed under the terms of the Creative Commons Attribution License (http://creativecommons.org/licenses/by/4.0), which permits unrestricted use, distribution, and reproduction in any medium, provided the original work is properly cited. 
$\mathrm{RM}$ at PEEP $=26 \mathrm{cmH}_{2} \mathrm{O}$. Recruitable CT-collapse was calculated by multiplying the difference between CT-collapse at a certain PEEP-step and "non-recruitable collapse" by $100 \%$ and then dividing this product by the difference between total lung mass and "non-recruitable collapse". EIT-collapse was calculated based on analysis of changes in EIT-pixel compliance [1]. The latter was estimated considering that local tidal volumes correlate well with local impedance variations. The concept used here assumes that the best compliance of a lung compartment reflects the number of functional lung units in that compartment, which, once opened, have equivalent compliances $[1,3]$. Thus, the relative amount of collapse (amount of lost units) within a given pixel can be inferred from the decrease in pixel compliance in relation to its "best compliance" [1,3]. Bland-Altman plots and within-subject linear regression were used for statistical analysis [2].

\section{Results}

We analyzed 60 data points from 11 pigs (weight 39 (range $37-42) \mathrm{kg}$ ). We found a strong within-subject correlation and clinically acceptable agreement between CT- and EIT-collapse (Figure 1) [4].

\section{Conclusion}

Our results support the potential of EIT for non-invasive bedside assessment of recruitable collapse.

\section{Authors' details}

'University Leipzig, Department of Anesthesiology and Intensive Care

Medicine, Leipzig, Germany. ${ }^{2}$ Faculdade de Medicina da Universidade de Sao Paulo, Sao Paulo, Brazil. ${ }^{3}$ Veterinary Medicine Faculty of University of Leipzig, Leipzig, Germany.

\section{Published: 1 October 2015}

\section{References}

1. Costa E: Intensive Care Med 2009

2. Reske A: Crit Care Med 2013.

3. Hickling K: Crit Care Med 2007.

4. Critchley LAH: J Clin Monit 1999.

doi:10.1186/2197-425X-3-S1-A995

Cite this article as: Hammermüller et al:: Quantification of lung collapse during peep-titration by electrical impedance tomography in

experimental ards - comparison with quantitative ct analysis. Intensive

Care Medicine Experimental 2015 3(Suppl 1):A995.

\section{Submit your manuscript to a SpringerOpen ${ }^{\circ}$ journal and benefit from:}

- Convenient online submission

- Rigorous peer review

- Immediate publication on acceptance

- Open access: articles freely available online

- High visibility within the field

- Retaining the copyright to your article

Submit your next manuscript at $\gg$ springeropen.com 